\title{
Aural and Nasal Temperature Measurements Using an Infrared Thermometer vs Conventional Axillary and Oral Measurements
}

\author{
Fadlullah Aksoy, Yavuz Selim Yıldırım*, Bayram Veyseller and Hasan Demirhan
}

\author{
Haseki Research and Training Hospital, Department of Otorhinolaryngology and Head and Neck Surgery, Istanbul, \\ Turkey
}

\begin{abstract}
Introduction and Aim: The aim of the present study was to compare aural temperature measurements with conventional methods (axillary and oral) in patients with unilateral tympanic membrane perforation or myringosclerosis. The study also aimed to test the potential nasal use of infrared thermometer.

Materials and Methods: Forty-four adult patients with monoaural tympanic membrane perforation and 29 adult patients with monoaural myringosclerosis were included in this prospective study conducted between June 2007 and November 2008. The contralateral ears of the patients were normal. Inter-aural, axillary, oral and nasal temperature measurement results of the patients were compared.

Results: Similar measurement results were obtained from the two ears in patients with monoaural perforation $(\mathrm{P}=0.7780$, $\mathrm{SD} \pm$ 0.3189). Similarly, in patients with monoaural myringosclerosis, no statistically significant difference was found between the measurements from the normal and diseased ear $(P=0.9346, S D \pm 0.2244)$. Measurements obtained by using nasal infrared thermometer was significantly lower compared to aural, axillary and oral measurements $(\mathrm{p}<0.0001)$.

Conclusion: Perforation of tympanic membrane and myringosclerosis are usually asymptomatic and their presence does not effect the aural temperature measurements done by an infrared tympanic thermometer. Nasal temperature measurement by an infrared thermometer is not a reliable method, as it gives significantly lower results than actual body temperature.
\end{abstract}

Keywords: Temperature measurement, infrared ear thermometry, digital thermometer, mercury in-glass thermometer, thermistor, fever measurement.

\section{INTRODUCTION}

Fever is a quite sensitive indicator of infectious disease. The thermometer, which was developed more than a century ago, measures heat conducted from the skin or mucous membranes to an adjacent probe. Following the description of infrared thermometry by Hughes et al. (1985), noncontacted infrared tympanic thermometry (ITT) has been added to the display of clinical techniques [1]. This method provides a non-invasive temperature reading within seconds and requires minimum cooperation. It is easy to use, does not require the removal of the cloths and mucous membranes are not directly contacted. The method is well accepted by pediatric patients, adults, parents and nurses at emergency room, outpatient clinic and hospital settings [2].

The blood supply to the ear canal and the tympanic membrane is from the maxillary and middle meningeal arteries, which are branches of the external carotid artery. Because both the ear canal and the tympanic membrane have no inherent metabolic activity, the local temperature is primarily determined by their respective blood supply. Therefore, the tympanic membrane temperature should closely represent the hypothalamic temperature [3].

*Address correspondence to this author at the Haseki Eğitim ve Araştırma Hastanesi, Kulak Burun Boğaz Kliniği, 34089 Fatih/Istanbul, Turkey; Tel: +90 212 5294400, Ext: 1286; Fax: +90 212 5103701;

E-mail: dryavuzselim@yahoo.com
The mercury glass thermometer is among the most frequently used temperature measurement tools. Currently, electronic thermometers have replaced the mercury glass thermometers in clinical settings. These electronic ear thermometers measure the radiant heat emitted from the tympanic membrane and external ear canal [4]. These measurements may be influenced by the following factors: presence of otitis media or external otitis, canal wall down surgery and a narrow external ear canal (with or without excessive hair) [2,5]. Such factor may result in inaccurate results. On the other hand, according to several studies, presence of effusion (otitis media with effusion) or ventilation tube does not effect ITT results [6,7].

The aim of the present study was to compare simultaneous temperature measurements obtained from the diseased and normal ears of patients with unilateral tympanic membrane perforation or myringosclerosis (with intact contralateral ear), using an infrared tympanic thermometer, which is a practical, convenient and non-invasive device requiring minimum cooperation. We also aimed to compare these with the results of classical body temperature measurement methods: oral measurements using a digital thermometer and axillary measurements with a mercury thermometer.

Nasal region is a promptly visible and accessible part of the body and it is more vascular than ears. We also compared nasal temperature measurements done by using an infrared 
thermometer with simultaneous aural, axillary and oral measurements, in order to examine its potential clinical use.

\section{MATERIALS AND METHODS}

Selected patients that admitted to the otorhinolaryngology outpatient clinics of Haseki Training and Research Hospital between June 2007 and November 2008 and diagnosed with unilateral tympanic membrane perforation or myringosclerosis with contralateral intact ear based on otoscopic examination were included in the present study. Exclusion criteria were as follows: presence of cerumen, otorrhea or excessive hair in external auditory canal, an extremely narrow canal, evidence of infection, previous ear surgery or presence of ear pathology. In order to reduce the effects of variables such as age and gender, patients were allocated into matched groups. Patients receiving systemic medications, patients with a current infection that may cause fever or a body weight $>100 \mathrm{~kg}$ were also excluded.

Verbal consent was obtained from all patients. Measurements were done at constant room temperature $\left(22 \pm 1^{\circ} \mathrm{C}\right)$ by the same physician using the same methods. Patients were not allowed to consume hot or cold beverages (e.g. coffee and tea) or smoke within 2 hours before the measurements and they were allowed to rest for 5 minutes just prior to the measurements. All measurements were done in supine position in order to reduce any effect of posture. Monoaural tympanic membrane perforation group patient is consisted of $\% 20$ large peforation (total) and $80 \%$ small perforation. Size of perforation are too immaterial to be clinically relevant. There fore, no emphasis. Simultaneous measurements were obtained from the two ears, axilla, mouth and nose.

\section{Procedure}

Auricle was pulled posteriorly and superiorly for better exposure of the canal. Then the probe of non-contact infrared tympanic thermometer was placed into the external auditory canal in the direction of the eye so that it will face tympanic membrane. For each measurement, the probe was kept in place until the triple beep sound. The average of two consecutive measurements were recorded and a fully calibrated infrared tympanic thermometer was used (Braun Thermoscan ${ }^{\circledR}$ IRT 3520 Germany).

For the measurements of oral temperature, disposable tip of a regular digital thermometer (Omron Eco-Temp Digital Thermometer, Europa) was placed sublingually near frenulum and kept in place until acoustic signals. Patient was instructed to breathe through the nose and not to speak. The average of two consecutive measurements were recorded.

For axillary measurements, the most common type of mercury thermometer was used (mercury-in-glass thermometer). Before the measurement, axillary region was wiped with a dry towel and the thermometer was shaken to ensure that baseline reading was below $35.8 \mathrm{C}^{\circ}$. The probe was placed to the upper part of axilla and the patient was instructed to hold the arm in adduction. The reading was recorded after 4 to 5 minutes.

Prior to nasal temperature measurements, the patient was instructed to breathe through the mouth and not to move. First, the probe (tip) of the infrared tympanic thermometer was placed into right nasal vestibule so that it will face inferior concha and kept in place until the triple beep sound. Two consecutive measurements were made and their average was recorded. Then the same procedures were repeated for the left nasal vestibule. Braun Thermoscan ${ }^{\circledR}$ IRT 3520 (Germany) infrared thermometer was used for the measurements.

\section{Statistical analysis}

Due to the absence of a dependent variable in the study, paired sample $t$ test was used for the comparisons of two groups and ANOVA was used for the comparisons of more than two groups. Both groups had normal distribution and a

Table 1. Descriptive Statistical Data of Temperature Measurements for the Patients with Tympanic Membrane Perforation (n 44) and Tympanosclerosis (n 29)

\begin{tabular}{|c|c|c|c|c|c|c|c|c|c|c|}
\hline $\begin{array}{c}\text { Summary Statistics } \\
\text { Table } 1\end{array}$ & $\mathbf{N}$ & Mean & $95 \% \mathrm{CI}$ & Variance & SD & RSD & SEM & Median & Minimum & Maximum \\
\hline normal ear & 44 & 37,034 & $36,919-37,149$ & 0,1428 & 0,3778 & 0,0102 & 0,05696 & 37,100 & 36,300 & 37,800 \\
\hline perforated ear & 44 & 37,048 & $36,961-37,134$ & 0,08116 & 0,2849 & 0,00769 & 0,04295 & 37,100 & 36,400 & 37,500 \\
\hline axillary & 44 & 36,700 & $36,554-36,846$ & 0,2302 & 0,4798 & 0,01307 & 0,07234 & 36,800 & 35,600 & 37,500 \\
\hline oral & 44 & 37,050 & $36,923-37,177$ & 0,1733 & 0,4162 & 0,01123 & 0,06275 & 37,100 & 36,100 & 38,000 \\
\hline right nasal & 44 & 32,850 & $32,321-33,379$ & 3,0240 & 1,7390 & 0,05294 & 0,2622 & 33,400 & 29,700 & 35,500 \\
\hline left nasal & 44 & 33,475 & $32,961-33,989$ & 2,8549 & 1,6897 & 0,05048 & 0,2547 & 34,100 & 30,000 & 36,600 \\
\hline normal ear & 29 & 37,117 & $37,003-37,231$ & 0,09005 & 0,3001 & 0,008085 & 0,05572 & 37,100 & 36,600 & 37,600 \\
\hline tympanosclerosis & 29 & 37,121 & $37,027-37,214$ & 0,06027 & 0,2455 & 0,006614 & 0,04559 & 37,100 & 36,800 & 37,700 \\
\hline axillary & 29 & 36,928 & $36,766-37,089$ & 0,1799 & 0,4242 & 0,01149 & 0,07877 & 37,000 & 36,000 & 37,700 \\
\hline oral & 29 & 37,183 & $37,058-37,307$ & 0,1072 & 0,3274 & 0,008805 & 0,0608 & 37,200 & 36,400 & 37,900 \\
\hline right nasal & 29 & 32,890 & $32,276-33,504$ & 2,6052 & 1,6141 & 0,04908 & 0,2997 & 32,800 & 30,100 & 35,600 \\
\hline left nasal & 29 & 33,062 & $32,362-33,762$ & 3,3874 & 1,8405 & 0,05567 & 0,3418 & 33,300 & 30,100 & 36,300 \\
\hline
\end{tabular}


$\mathrm{p}$ value $<0.05$ was considered significant (at $95 \% \mathrm{CI}$, for $\alpha=0.05$ and $1-\beta=0.80$ ). For the analysis of data, SPSS 16.0 .1 for Windows and MedCalc ${ }^{\circledR}$ Turkey v10.0.1 software packages were used.

\section{RESULTS}

A total of 44 patients with perforation of tympanic membrane were included ( 22 male and 22 female, mean age: $32.5 \pm 12.8$ years, age range: $10-62 \mathrm{y}$ ). On the other hand, the number of patients with myringosclerosis was 29 (15 male and 14 female, mean age: $33.5 \pm 12.4$ years, age range: 13 $65)$. The mean temperatures, minimum, maximum and median values at $95 \% \mathrm{CI}$, and standard deviation (SD), relative standard deviation (RSD) and median standard error (SEM) values of the two groups are shown in Table $\mathbf{1}$. Among patients with monoaural perforation, similar temperature measurement results were obtained from the diseased and contralateral normal ear $(\mathrm{P}=0.7780, \mathrm{SD} \pm$ 0.3189) (Fig. 1). The same relation was also true for the patients with monoaural myringosclerosis $(\mathrm{P}=0.9346, \mathrm{SD} \pm$ $0.2244)$. (Fig. 2). Among patients with perforation $(n=44)$, the mean temperature measured from the contralateral normal ear was similar to the oral temperature $(\mathrm{P}=1.000$, SE \pm 0.0771); however, statistically significant differences was found between axillary temperature $(p<0.014$, SE \pm $0.094)$, right nasal temperature $(\mathrm{p}<0.0001, \mathrm{SE} \pm 0.266)$ and left nasal temperature ( $<<0.0001$, SE \pm 0.261$)$ (Fig. 3). On the other hand, among patients with myringosclerosis $(n=29)$, the mean temperature measured from the contralateral normal ear was similar to the axillary $(\mathrm{P}=0.2841, \mathrm{SE} \pm$
$0.0761)$ and oral temperature $(\mathrm{P}=1.0000, \mathrm{SE} \pm 0.0706)$, whereas it significantly differed from right $(\mathrm{p}<0.0001, \mathrm{SE} \pm$ $0.297)$ and left nasal temperature $(p<0.0001$, SE \pm 0.334) (Fig. 4).

\section{DISCUSSION}

Over the past decade, ITT has increase wider acceptance. Nurses, parents and children have rated it higher in terms of rapidity, ease of use, cleanliness, safety and cost effectiveness [8]. This method of temperature measurement through ear offers advantages for both patients and nurses, including elimination of the needs for contacting mucous membranes and special handling procedures, which may be particularly important in terms of infection control [9]. The use of ITT for temperature measurements is step by step becoming more common in hospital settings, as this method allows users to quickly and non-invasively measure body temperature by inserting a directional probe into the ear canal. ITT offers a more comfortable and less stressful measurement. Infrared thermometers detect the infrared radiation emitted from the tympanic membrane and external auditory canal [10].

Several features of the external ear canal such as a narrow canal, presence of excessive hair or cerumen, presence of external otitis and canal wall down surgery invalidate the ITT measurements [11]. Presence of serous otitis media or inserted ventilation tube does not affect these measurements [12]. In the present study, ITT measurements were not affected by the presence of myringosclerosis or tympanic membrane perforation.

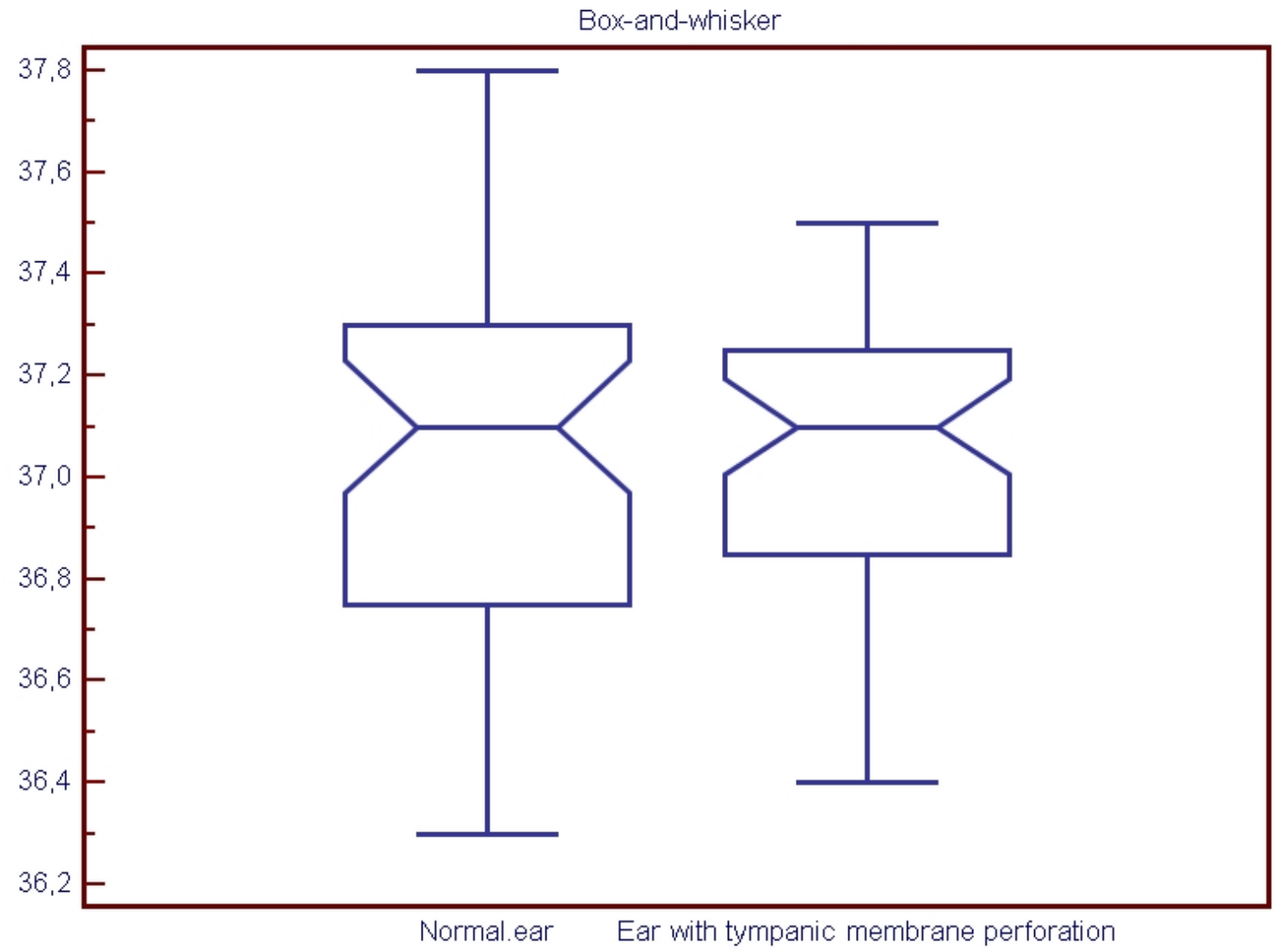

Fig. (1). Graphic representation of the measurements from the normal ear and from the ear with tympanic membrane perforation. 
Dot \& line diagram

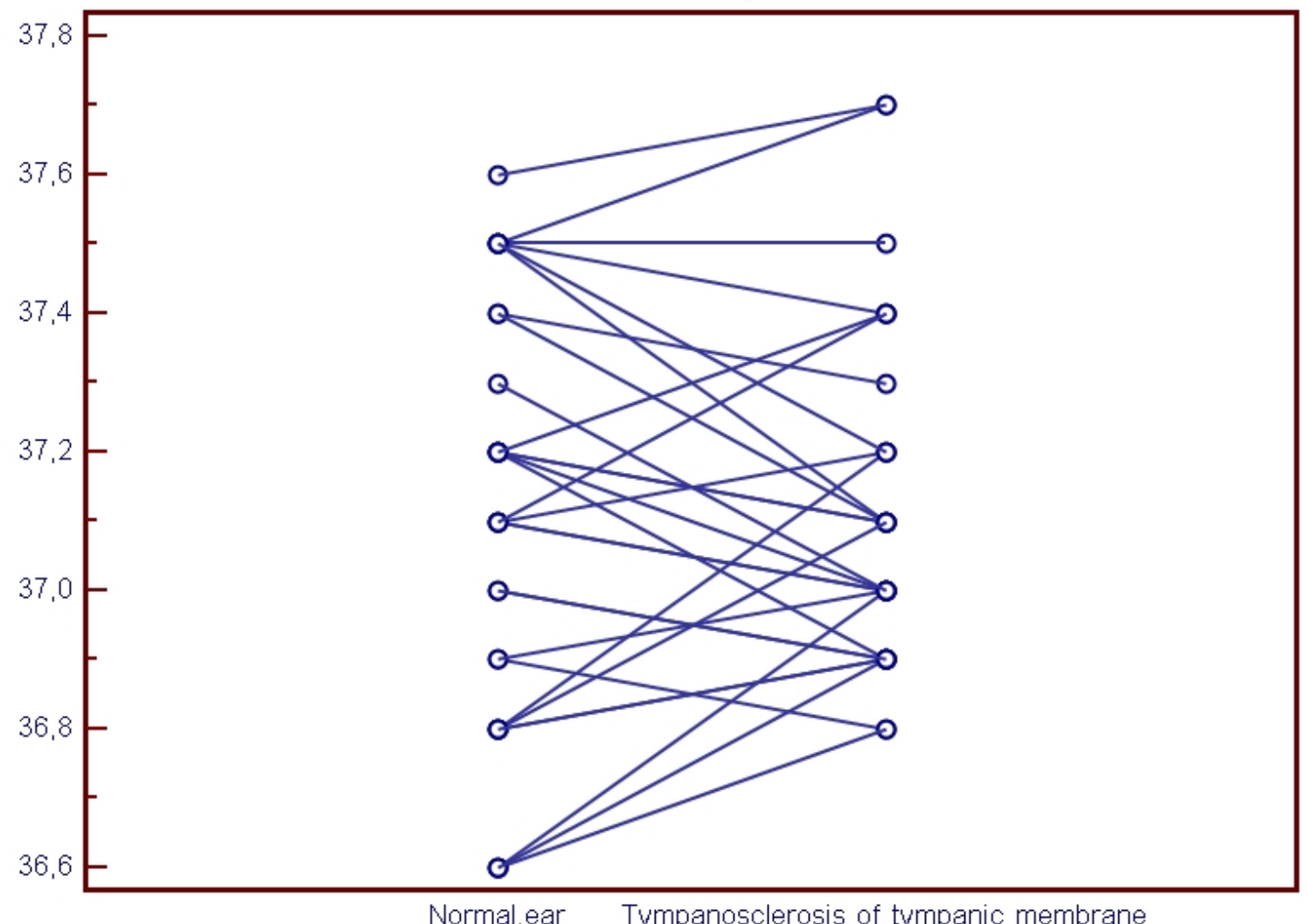

Fig. (2). Diagram of the data from the normal ear and from the ear with tympanosclerosis.

Box-and-whisker Means (error bars: $95 \% \mathrm{Cl}$ for mean)

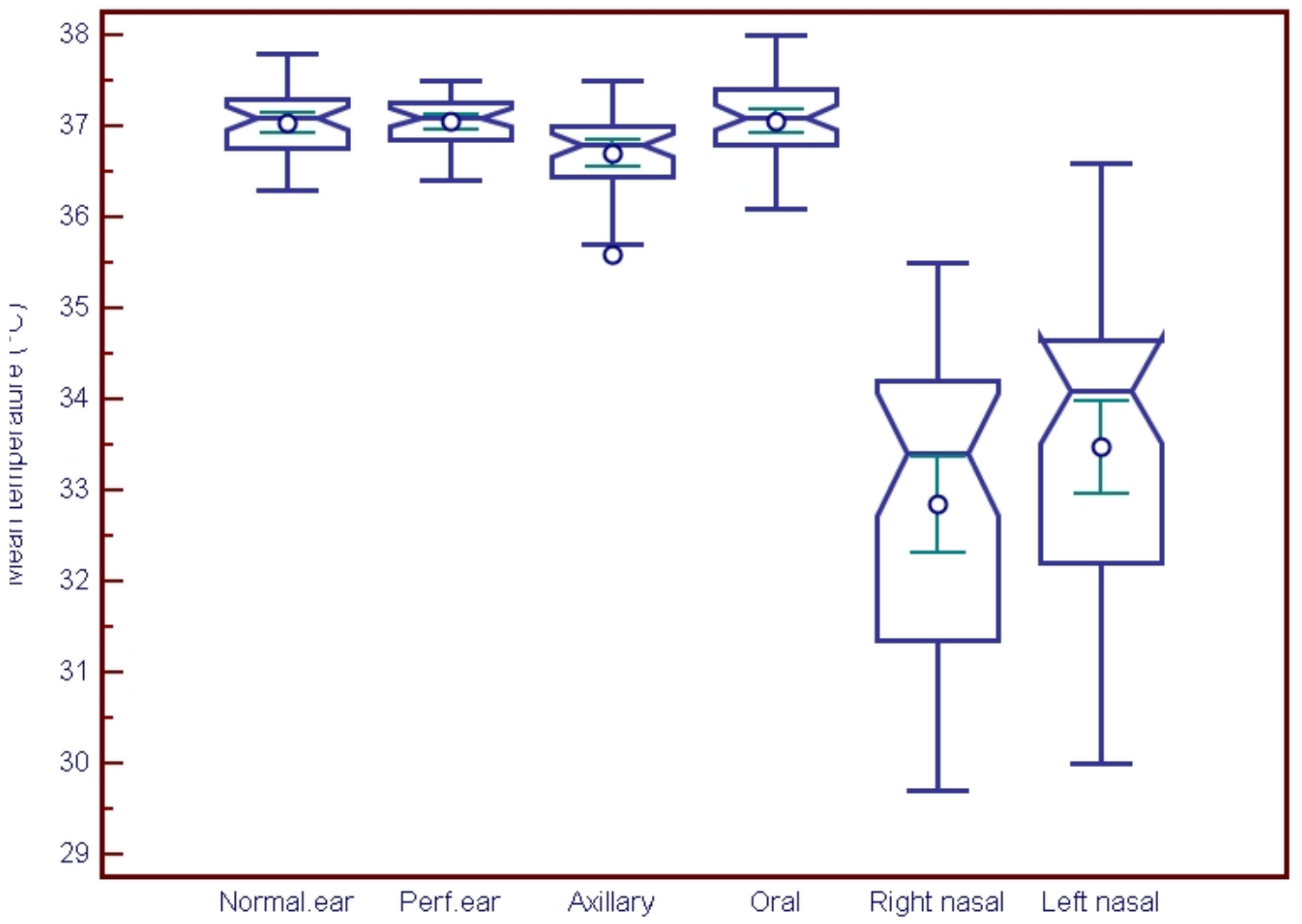

Fig. (3). Axillary, oral, right nasal and left nasal fever measurements with $95 \%$ confidence intervals in patients with unilateral perforation and normal contralateral ear. 


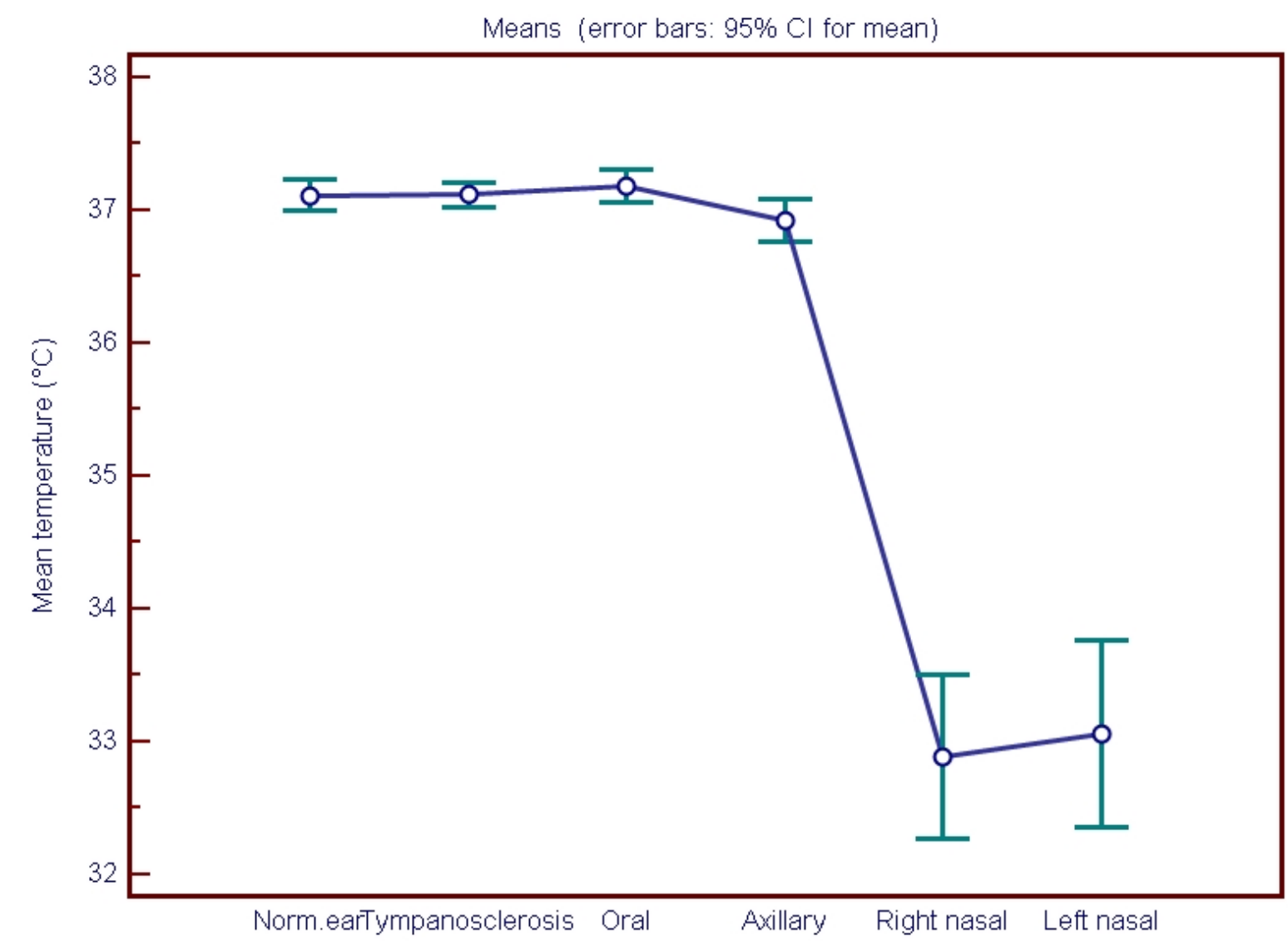

Fig. (4). Axillary, oral, right nasal and left nasal fever measurements with $95 \%$ confidence intervals in patients with unilateral tympanosclerosis and normal contralateral ears.

In intensive care units and emergency departments, temperature measurement is an essential component of patient assessment and management. An optimal temperature measurement device should be minimally invasive and should provide rapid results in a reliable, accurate and safe manner to support clinical decisions [13]. As noted in previous studies, axillary temperature measurements significantly underestimate core temperature when compared to aural and oral measurements.

The primary objective of the present study was to examine whether ITT measurement is an accurate and reliable indicator of core temperature in adults, when compared to oral, axillary and nasal measurements. We found a close agreement between ITT measurements and oral measurements, rather than axillary measurements.

In the study of Dodd SR et al. [13] infrared thermometers failed to measure accurately the temperatures of 3 out of 10 febrile children; and the authors concluded that ITT was not suitable for the measurement of body temperature. According to M Sund-Levander et al. [14] all measurements should be made from the same ear using the same device and method, and if possible, private devices should be used for each individual or otherwise hospital type of devices are recommended.

Many studies have been published examining the accuracy of ITT in comparison with core temperature measurement techniques $[3,4,8,15]$. Despite the heterogeneity of conclusions, ITT is still widely used in pediatric practices and in emergency rooms $[4,8,9,16,17]$.

Occasionally the site for temperature measurement may need to be changed in response to the patient's condition. For example, in a patient with a recent need for oxygen administration, a switch from oral to tympanic measurements may be more suitable. Because, as a result of the difficulties with the correct positioning of the probe in the sublingual pocket, inaccurate readings may occur. A child endeavor against rectal temperature measurement may be better served if the nurse selects the axillary or tympanic sites [18].

Nasal mucosal temperature was measured in 71 healthy subjects with an electronic thermometer and no correlation was found between the nasal mucosal temperature and age or sex [19]. Using ITT, Willat DJ [20] measured significantly higher nasal temperature values during expirium compared to inspirium and temperature of the nasal mucosa was parallel to the atmospheric temperature. In the present study, nasal mucosa did not represent a suitable site for an accurate measurement of body temperature, which may be explained by the following: (i) it is a dynamic and an open space at its both ends and it is an erectile organ, (ii) it is involved both in inspirium and expirium, and (iii) compliance issues such as the need for holding the breathe during measurements.

\section{SUMMARY}

ITT measurements agreed more closely with core temperature than nasal and axillary measurements, in adults with perforation or myringosclerosis. ITT and oral 
temperature measurements had minimal variability compared to axillary measurements. Right and left nasal temperature measurements were inaccurate and highly variable; and they did not agree with core temperature.

\section{CONCLUSION}

ITT is a reliable, non-invasive, practical and accurate method for the detection of fever in adults. ITT has gained the confidence of nurses for the measurement of this important vital sign. The recommended site of measurement should assure patient comfort and cooperation and it should be appropriate for the nurse; and this strategy provides better compliance for frequent fever measurements.

\section{REFERENCES}

[1] Hughes WT, Patterson GG, Thornton D, Williams BJ, Lott L, Dodge R. Detection of fever with infrared thermometry: a feasibility study. J Infect Dis 1985; 152: 301-6.

[2] Schmäl F, Loh-van den Brink M, Stoll W. Effect of the status after ear surgery and ear pathology on the results of infrared tympanic thermometry. Eur Arch Otorhinolaryngol 2006; 263: 105-10.

[3] Nimah MM, Bshesh K, Callahan JD, Jacobs BR. Infrared tympanic thermometry in comparison with other temperature measurement techniques in febrile children. Pediatr Crit Care Med 2006; 7: 4855.

[4] Kocoglu H, Goksu S, Isik M, Akturk Z, Bayazit YA. Infrared tympanic thermometer can accurately measure the body temperature in children in an emergency room setting. Int J Pediatr Otorhinolaryngol 2002; 65: 39-43.

[5] Mandell DL, Pearl AW, Rothschild MA. Influence of minor ear surgery on infrared tympanic thermometry. Arch Otolaryngol Head Neck Surg 2001; 127: 547-52.

[6] Robb PJ, Shahab R. Infrared transtympanic temperature measurement and otitis media with effusion. Int $\mathrm{J}$ Pediatr Otorhinolaryngol 2001; 59: 195-200.

[7] Tomkinson A, Roblin DG, Quine SM, Flanagan P. Tympanic thermometry and minor ear surgery. J Laryngol Otol 1996; 110 : 454-5.
[8] Barton SJ, Gaffney R, Chase T, Rayens MK, Piyabanditkul L. Pediatric temperature measurement and child/parent/nurse preference using three temperature measurement instruments. J Pediatr Nurs 2003; 18: 314-20.

[9] Brennan DF, Falk JL, Rothrock SG, Kerr RB. Reliability of infrared tympanic thermometry in the detection of rectal fever in children. Ann Emerg Med 1995; 25: 21-30.

[10] McCarthy PW, Heusch AI. The vagaries of ear temperature assessment. J Med Eng Technol 2006; 30: 242-51.

[11] Devrim I, Kara A, Ceyhan M, et al. Measurement accuracy of fever by tympanic and axillary thermometry. Pediatr Emerg Care 2007; 23: 16-9.

[12] Pandey A, Ingrams DR, Jones M, Raman R, Marks ND. Reliability of a tympanic thermometer in measuring temperatures in children after minor ear surgery. J Laryngol Otol 2006; 120: 375-7.

[13] Dodd SR, Lancaster GA, Craig JV, Smyth RL, Williamson PR. In a systematic review, infrared ear thermometry for fever diagnosis in children finds poor sensitivity. J Clin Epidemiol 2006; 59: 354-7.

[14] Sund-Levander M, Grodzinsky E, Loyd D, Wahren LK. Errors in body temperature assessment related to individual variation, measuring technique and equipment. Int J Nurs Pract 2004; 10: 216-23.

[15] Schuman AJ: The accuracy of infrared auditory canal thermometry in infants and children. Clin Pediatr 1993; 347-354.

[16] Khorshid L, Eșer I, Zaybak A, Yapucu U. Comparing mercury-inglass, tympanic and disposable thermometers in measuring body temperature in healthy young people. J Clin Nurs 2005; 14: 496500 .

[17] Bernardo LM, Clemence B, Henker R, Hogue B, Schenkel K, Walters P. A comparison of aural and rectal temperature measurements in children with moderate and severe injuries. J Emerg Nurs 1996; 22: 403-8.

[18] Bernardo LM, Henker R, O'Connor J. Temperature measurement in pediatric trauma patients: A comparison of thermometry and measurement routes. J Emerg Nurs 1999; 25: 327-9.

[19] Akerlund A, Bende M. Nasal mucosal temperature and the effect of acute infective rhinitis. Clin Otolaryngol Allied Sci 1989; 14: 52934.

[20] Willatt DJ. Continuous infrared thermometry of the nasal mucosa. Rhinology 1993; 3: 63-7. 